\title{
Conservação in vitro de mangabeira da região nordeste do Brasil
}

\author{
In vitro conservation of mangaba tree in Northeast Brazil
}

Aline de Jesus Sá ${ }^{I}$ Ana da Silva Lédo ${ }^{\text {II }}$ Carlos Alberto da Silva Lédo ${ }^{\text {III }}$

\section{RESUMO}

A mangabeira (Hancornia speciosa Gomes) é uma espécie cujas regiões de ocorrência natural vêm sofrendo grande pressão antrópica, a qual está provocando erosão genética em muitas populações nativas, principalmente da região Nordeste. Em virtude da existência de poucas coleções de mangabeira conservadas ex situ, evidencia-se a importância do desenvolvimento de um método alternativo e complementar para a conservação de germoplasma dessa espécie. A utilização de técnicas de cultura de tecidos de plantas para a conservação de recursos genéticos apresenta diversas vantagens sobre a conservação de germoplasma no campo, destacando-se a economia de recursos financeiros para a manutenção das coleções, redução de riscos fitossanitários e intempéries climáticas. Por esse motivo, o presente trabalho teve como objetivo avaliar a eficiência de regulador osmótico (manitol) e inibidor de crescimento (ácido abscísico) na conservação in vitro de microestacas de mangabeira por crescimento lento. As culturas foram mantidas em meio MS com 3\% de sacarose e $0,6 \%$ de agar. Os experimentos foram conduzidos em delineamento inteiramente casualizado, em sala de crescimento com temperatura variando de $26 \pm 2^{\circ} \mathrm{C}$, umidade relativa do ar média em torno de $70 \%$ e fotoperiodo de 12 horas de luz branca fria $\left(52 \mu \mathrm{mol} \mathrm{m} \mathrm{m}^{-2} \mathrm{~s}^{-1}\right.$ de irradiância). Foram avaliadas cinco concentrações de manitol (0, 10, 15 e $\left.20 \mathrm{~g} \mathrm{~L}^{-1}\right)$. Na presença de manitol, o comprimento da parte aérea apresentou valores numéricos inferiores à testemunha, mas, aos 90 dias de cultivo in vitro, foi observado efeito deletério do manitol nas microestacas. Em relação ao ácido abscísico, foram testadas cinco concentrações $\left(0 ; 0,5 ; 1 ; 2\right.$ e $\left.4 \mathrm{mg} L^{-1}\right) \mathrm{em}$ interação com dois tipos de vedação de frascos (tampa plástica rosqueada e papel aluminio) e dois tipos de explantes (microestacas apicais e basais). O ácido abscísico (0,5mg $\left.\mathrm{L}^{-1}\right)$ apresentou melhores resultados para a conservação in vitro de microestacas de plântulas de mangabeira cultivadas em frascos vedados com papel alumínio. Não houve efeito significativo do tipo de explante.

Palavras-chave: Apocynaceae, crescimento lento, manitol, ácido abscísico.

\begin{abstract}
The mangaba tree (Hancornia speciosa Gomes) is a species whose natural occurrence has suffered great human pressure, which is causing genetic erosion in many populations, especially in the Northeast Brazil. Due to the existence of few collections of mangaba tree preserved ex situ, it's important to develop a complementary and alternative method to germplasm conservation of this species. The use of techniques of plant tissue culture for conservation of plant genetic resources presents several advantages over germplasm conservation in the field, especially when focusing cost reduction for the maintenance of collections, sanitary risk and weather problems. The present research aimed to evaluate the effectiveness of regulators osmotic mannitol and the growth inhibitor abscisic acid on the in vitro conservation of mangaba microcutting under slow growth. The cultures were maintained in MS medium with 3\% sucrose and $0.6 \%$ of agar. The experiments were conducted in a randomized blocks design in a growth room with temperature ranging from $26+2^{\circ} \mathrm{C}$, average relative humidity around $70 \%$ and photoperiod of 12 hours of

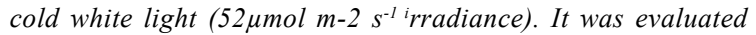
five concentrations of mannitol $(0,10,15$ and $20 \mathrm{~g} \mathrm{L-1)}$. Mannitol in the presence of the length of shoots showed values below the control, but after 90 days of in vitro culture was observed deleterious effect of mannitol in microcutting. It was tested five concentrations of abscisic acid $(0 ; 0.5 ; 1 ; 2$ and $4 m g L^{-1}$ ) in interaction with two types of sealing bottles (plastic
\end{abstract}

'Núcleo de Estudos em Recursos Naturais, Universidade Federal de Sergipe (UFS), São Cristóvão, SE, Brasil.

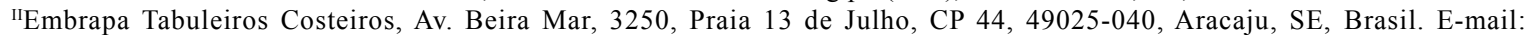
analedo@cpatc.embrapa.br. Autor para correspondência.

IIIEmbrapa Mandioca e Fruticultura Tropical, Cruz das Almas, BA, Brasil. 
cover and threaded aluminum foil ) and two types of explants (apical and basal microcutting). Abscisic acid (0.5mg $\left.\mathrm{L}^{-1}\right)$ showed better results for in vitro conservation of seedling of mangaba microcutting grown in flasks sealed with aluminum foil. There was no significant effect of explant type.

Key words: Apocynaceae, slow growth, mannitol, abscisic acid.

\section{INTRODUÇÃO}

Em função da crescente ocupação de áreas de vegetação nativa e da sensível erosão genética observada em muitas espécies de plantas que apresentam potencial de utilização alimentícia ou medicinal, torna-se evidente a necessidade do desenvolvimento e aperfeiçoamento de técnicas de conservação de germoplasma dessas espécies, de forma que ele esteja disponível para utilização futura.

A mangabeira (Hancornia speciosa Gomes) é uma espécie nativa encontrada em várias regiões do país e apresenta o maior potencial de uso imediato entre as fruteiras nativas da região Nordeste (FERREIRA et al., 2005). Percebe-se que nessa região está ocorrendo erosão genética em muitas populações nativas da espécie, em consequência da exploração agrícola ou ocupação imobiliária de áreas remanescentes de mangabeira, ressaltando-se a necessidade de métodos de conservação eficientes que possam minimizar os riscos de extinção dessa espécie.

A conservação de germoplasma de mangabeira em campo já é realizada por órgãos de pesquisa em alguns estados nordestinos, mas a vulnerabilidade que os acessos apresentam nesse tipo de conservação é alta, o que ressalta a necessidade do desenvolvimento de técnicas complementares de conservação. Como a formação de bancos de sementes dessecadas de mangabeira mantidas em condições de baixa temperatura é inviável devido à recalcitrância das sementes, a conservação in vitro pode ser considerada potencial.

A aplicação de técnicas biotecnológicas de cultura de tecidos tem permitido que coleções de germoplasma de várias espécies de plantas, como a oliveira (Olea europaea L.) e a bananeira (Musa sp.) (LAMBARDI et al., 200; INIBAP, 2006), sejam formadas e conservadas por longos períodos, possibilitando assim que o material vegetal de interesse se torne disponível para recuperação e possível utilização futura. Uma das maneiras de conservar material vegetal é através da técnica de crescimento lento, através da qual o metabolismo das plantas pode ser reduzido pela da modificação nas condições químicas do meio de cultivo.
Trabalhos de conservação in vitro por crescimento lento têm sido desenvolvidos e têm mostrado viabilidade para diferentes espécies de importância econômica, como cana-de-açúcar (Saccharum officinarum L.) (LEMOS et al., 2002), abacaxi (Ananas comosus) (CANTO et al., 2004), maracujazeiro (Passiflora giberti N. E. Brown.) (FARIA et al, 2006), coco (Cocos nucifera L.) (LÉDO et al., 2007) e açaí (Euterpe oleracea Mart.) (OLIVEIRA et al., 2001). Apesar dos resultados promissores, não existe um protocolo padrão de conservação que possa ser aplicado para todas as espécies, pois as respostas podem variar em função da espécie, cultivar, tipo de explante dentre outros fatores.

O estabelecimento de protocolos de conservação in vitro para a mangabeira nativa da região Nordeste é necessário, como forma alternativa e complementar à conservação de germoplasma de mangabeira em campo. Diante do exposto, este trabalho teve por objetivo avaliar o efeito do manitol, do ácido abscísico, tipo de microestaca e fatores físicos (frasco e vedação) no crescimento de microestacas de mangabeira, visando ao estabelecimento de um protocolo de conservação por crescimento lento.

\section{MATERIAL E MÉTODOS}

Para o estudo da conservação in vitro da mangabeira, variedade botânica do Nordeste, foram utilizados como explantes plântulas germinadas in vitro, sendo que as sementes usadas para germinação foram coletadas de frutos maduros de acessos da população nativa de mangabeiras do Campo Experimental da Embrapa Tabuleiros Costeiros, em Itaporanga d' Ajuda, SE.

A assepsia e inoculação das sementes foram realizadas no Laboratório de Cultura de Tecidos de Plantas da Embrapa Tabuleiros Costeiros. Após a inoculação, em meio de cultura MS gelificado com $0,6 \%$ de agar e suplementado com $0,3 \%$ de sacarose, as culturas foram mantidas em sala de crescimento com temperatura variando de $26 \pm 2^{\circ} \mathrm{C}$, umidade relativa do ar média em torno de $70 \%$ e fotoperíodo de 12 horas, fornecido por luz branca fria e densidade de fluxo de fótons de $52 \mu \mathrm{mol} \mathrm{m}-2 \mathrm{~s}-1$ de irradiância.

Experimento I- Efeito do manitol na conservação in vitro de microestacas de mangabeira

Para avaliar o efeito do manitol na conservação in vitro de microestacas de mangabeira, foram utilizadas microestacas de aproximadamente $7 \mathrm{~cm}$ de comprimento, provenientes de plântulas de mangabeira germinadas in vitro com 50 dias de cultivo. 
As microestacas foram inoculadas em frascos de vidro tipo maionese com capacidade para $250 \mathrm{~mL}$, contendo $30 \mathrm{~mL}$ do meio de cultura MS gelificado com $0,6 \%$ de ágar e com $3 \%$ de sacarose, suplementado com $1 \mathrm{mg} \mathrm{L}^{-1}$ de AIA e $1 \mathrm{mg} \mathrm{L}^{-1}$ de BAP, variando as concentrações de manitol: $0 ; 10 ; 15$ e $20 \mathrm{~g} \mathrm{~L}^{-1}$.

O experimento foi instalado em parcelas subdivididas no tempo, sendo a parcela constituída de quatro tratamentos (quatro concentrações de manitol) e a subparcela de três tempos, com cinco repetições. A unidade experimental foi constituída de quatro frascos com uma microestaca cada. As avaliações foram realizadas aos 30, 60 e 90 dias da inoculação, observando-se o comprimento da microestaca $(\mathrm{cm})$ e número de folhas que sofreram abscisão (abscisão foliar).

Experimento II- Efeito do ácido abscísico, da posição e do tipo de vedação de frascos na conservação in vitro de microestacas de mangabeira

Para avaliar o efeito do ácido abscísico, da posição e do tipo de vedação de frascos na conservação in vitro de microestacas de mangabeira, plântulas de mangabeira germinadas in vitro (com aproximadamente $12 \mathrm{~cm}$ de comprimento) foram divididas em duas partes (basal e apical) e inoculadas em frascos contendo $30 \mathrm{~mL}$ do meio de cultura MS gelificado com $0,6 \%$ de ágar e suplementado com 3\% de sacarose. Foram avaliadas as seguintes concentrações de ácido abscísico: 0; 0,5; 1; 2 e 4mg L-1 e dois tipos de vedações de frasco: tampa plástica e papel alumínio.

O experimento foi instalado em parcelas subdivididas no tempo, sendo na parcela um fatorial $5 \times 2 \times 2$ (cinco concentrações de ABA, dois tipos de estacas e dois tipos de vedação de frascos) e na subparcela três tempos de avaliação, com quatro repetições. Cada unidade experimental foi constituída de um frasco contendo uma microestaca. As avaliações dos experimentos foram realizadas aos 30,60 e 90 dias após a inoculação, observando-se o comprimento da microestaca $(\mathrm{cm})$ e número de folhas que sofreram abscisão (abscisão foliar).

\section{Análises estatísticas}

Os modelos matemáticos dos experimentos foram: a) Experimento I: $Y i j=\mathrm{m}+M \mathrm{i}+d i+t j+(\mathrm{P} B * t) \mathrm{ij}$ + eij, onde: $Y i j=$ resposta da observação submetida ao $i$-ésimo nível de $M$ no tempo $j ; \mathrm{m}=$ média geral dos efeitos; $M i=$ efeito do $i$-ésimo de manitol; $t j=$ efeito do tempo $j$; $d i=$ erro aleatório associado a parcela principal; $\left(M^{*} t\right) i j=$ efeito da interação do $i$-ésimo nível de $M$ com o tempo $j$; eij = erro aleatório total e b)
Experimento II: Yijkl. $=\mathrm{m}+A B \mathrm{i}+E j+V k+T l+\left(A B^{*} E\right) \mathrm{ij}$ $+\left(A B^{*} V\right) \mathrm{ik}+\left(E^{*} V\right) \mathrm{jk}+\left(A B^{*} E^{*} V\right) \mathrm{ijk}+d i j k+\left(A B^{*} T\right) \mathrm{il}+$ $\left(E^{*} T\right) \mathrm{jl}+\left(V^{*} T\right) \mathrm{kl}+\left(A B^{*} E^{*} T\right) \mathrm{ijl}+\left(A B^{*} V^{*} T\right) \mathrm{ikl}+$ $\left(E^{*} V^{*} T\right) \mathrm{jkl}+\left(A B^{*} E^{*} V^{*} T\right) \mathrm{ijkl}+$ eijkl, em que: $Y i j \mathrm{kl}=$ resposta da observação submetida ao $i$-ésimo nível de $A B, j$-ésimo nível de $E$, $k$-ésimo nível de $V$ no tempo $l ; \mathrm{m}=$ média geral dos efeitos; $A B i=$ efeito do $i$-ésimo de ácido abscísico; $E j=$ efeito do $j$-ésimo nível de tipo de estaca; $V j=$ efeito do $k$-ésimo nível de tipo de vedação; $T 1=$ efeito do tempo $l ;(\ldots . . * \ldots)$ ij $=$ efeito das interações; eijkl = erro aleatório total.

Foi realizada a análise de variância considerando o delineamento inteiramente casualizado em parcela subdividida no tempo. Para as médias de manitol e de ABA foram ajustadas equações de regressão polinomial e as médias das posições, das vedações e do tempo de cultivo in vitro foram comparadas pelo teste de Tukey a 5\% de probabilidade de erro. As análises estatísticas foram realizadas utilizando-se o programa estatístico SISVAR.

\section{RESULTADOS E DISCUSSÃO}

Efeito do manitol na conservação in vitro de microestacas de mangabeira

Houve efeito significativo isolado do tempo de cultivo in vitro para o comprimento das microestacas, para a abscisão foliar e da interação do tempo de cultivo in vitro e manitol para o comprimento das microestacas aos 30, 60 e 90 dias e para abscisão foliar aos 90 dias (Figuras 1Ae 1B, Tabela 1). Não houve efeito do tipo da microestaca para todas as características avaliadas.

De acordo com a figura 1 , aos 30 dias de cultivo in vitro, o comprimento das microestacas variou segundo uma regressão quadrática, sendo menor nas concentrações de 15 e $20 \mathrm{~g} \mathrm{~L}^{-1}$ de manitol. Com a derivada calculada, o valor máximo para o comprimento é de 9,3 , correspondente à concentração de $5,96 \mathrm{~g} \mathrm{~L}^{-1}$ de manitol. Aos 60 e 90 dias de cultivo in vitro, o comprimento variou segundo uma regressão linear decrescente, ou seja, com menor comprimento em maiores concentrações de manitol. Apesar do resultado positivo na redução do alongamento das microestacas de mangabeira, fator importante para o processo de conservação in vitro, a utilização do manitol nas concentrações de 10,15 e $20 \mathrm{~g} \mathrm{~L}^{-1}$ não se mostrou viável para este propósito, uma vez que aos 90 dias de cultivo in vitro foi observado seu efeito deletério nas microestacas de mangabeira. FORTES \& PEREIRA (2001) alcançaram apenas 37\% de sobrevivência de hastes de batata em três meses de cultivo. Efeitos tóxicos do manitol foram reportados também por 


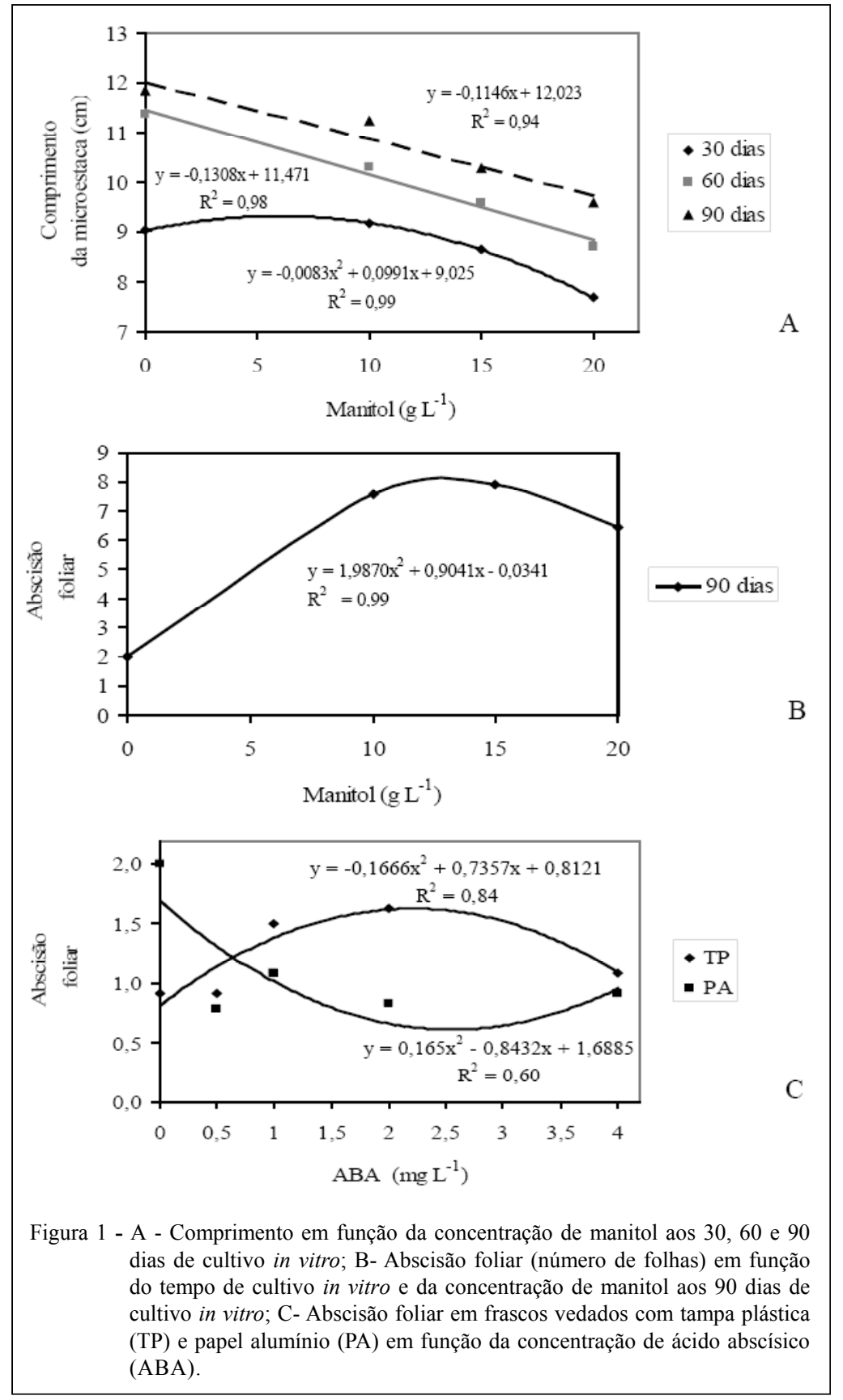

LEMOS et al. (2002) em cana-de-açúcar e por LÉDO et al. (2007) em plântulas de coqueiro anão verde de Jiqui do Brasil.

Observou-se um aumento da abscisão foliar com aumento do tempo de cultivo in vitro na presença de manitol, contribuindo sobremaneira para a senescência das microestacas (Tabela 1). $\mathrm{O}$ ambiente fechado, ao qual as plântulas ou explantes foram submetidos proporciona, de modo geral, o acúmulo de etileno, regulador de crescimento e responsável pela abscisão de folhas, frutos e flores. Esse regulador, mesmo em pequenas concentrações, pode ser fisiologicamente ativo e desencadear vários processos, dentre eles, a abscisão foliar (KERBAUY, 2004). Para a abscisão foliar, aos 30 e 60 dias de cultivo, em função da concentração de manitol, não foi possível estabelecer um modelo de regressão. Entretanto, aos 90 dias, variou segundo uma regressão quadrática, sendo menor na concentração $0 \mathrm{~g} \mathrm{~L}$ e a partir da concentração de $15 \mathrm{~g} \mathrm{~L}^{-1}$ de manitol (Figura 1B). Autores 
Tabela 1 - Médias da abscisão foliar, na presença de manitol, e médias de comprimento e abscisão foliar, na presença de ácido abscísico, de microestacas de mangabeira em função do tempo de cultivo in vitro.

\begin{tabular}{|c|c|c|}
\hline \multicolumn{3}{|c|}{ Microestacas na presença de manitol } \\
\hline \multicolumn{2}{|c|}{ Tempo de cultivo in vitro (dias) } & Abscisão foliar (número folhas) \\
\hline \multicolumn{2}{|l|}{30 dias } & $1,3250 \mathrm{~b}$ \\
\hline \multicolumn{2}{|l|}{60 dias } & $2,7400 \mathrm{~b}$ \\
\hline \multicolumn{2}{|l|}{90 dias } & $5,9775 \mathrm{a}$ \\
\hline \multicolumn{2}{|l|}{ CV $(\%)$} & 38,56 \\
\hline Tempo de cultivo in vitro (dias) & Comprimento das microestacas $(\mathrm{cm})$ & Abscisão foliar (número folhas) \\
\hline 30 dias & $6,9875 \mathrm{~b}$ & $0,6250 \mathrm{~b}$ \\
\hline 60 dias & $7,5263 \mathrm{ab}$ & $1,0750 \mathrm{~b}$ \\
\hline 90 dias & 8,1392 a & $1,8101 \mathrm{a}$ \\
\hline $\mathrm{CV}(\%)$ & 35,65 & 112,44 \\
\hline
\end{tabular}

Médias não seguidas pela mesma letra nas colunas diferem estatisticamente entre si pelo teste de Tukey a 5\% de probabilidade de erro.

têm relatado que algumas substâncias apresentam a capacidade de inibir a ação do etileno in vitro e interferirem no processo de abscisão foliar (RADEMACHER, 2000; NEPOMUCENO et al., 2007). Apesar de o manitol ter apresentado efeito deletério nas microestacas, sua presença a partir da concentração de $15 \mathrm{~g} \mathrm{~L}^{-1}$ no meio de cultura reduziu a abscisão foliar que normalmente é observada em culturas in vitro de mangabeira, devido ao acúmulo de etileno.

Efeito do ácido abscísico, da posição e do tipo de vedação de frascos na conservação in vitro de microestacas de mangabeira

Houve efeito significativo isolado do tempo de cultivo in vitro no comprimento das microestacas, na abscisão foliar, na interação da concentração de ácido abscísico e no tipo de vedação de frascos na abscisão foliar. Após 90 dias de cultivo in vitro, as microestacas apresentaram maior comprimento e abscisão foliar do que aos 30 dias (Tabela 1). Apesar do efeito isolado das concentrações de ABA sobre o comprimento e abscisão foliar não ter sido significativo, a abscisão foliar aos 90 dias de cultivo in vitro na presença de ABA apresentou menores valores numéricos quando comparado com microestacas mantidas na presença de manitol (Tabela 1 e Figura 1C).

Dependendo dos fatores que interferem na atuação do ácido abscísico, esse regulador do crescimento pode estimular ou inibir o crescimento vegetal (LEMOS et al., 2002). Em cana-de-açúcar, concentrações de ABA inferiores ou superiores a $1 \mathrm{mg}$ $\mathrm{L}^{-1}$ favorecem o crescimento, porém, na presença $1 \mathrm{mg}$ $\mathrm{L}^{-1}$ desse regulador de crescimento, ocorre inibição do crescimento nos explantes, sem redução da sua viabilidade (LEMOS et al., 2002). A presença de ABA $\left(0,01\right.$ a $\left.10 \mathrm{mg} \mathrm{L}^{-1}\right)$ inibiu a emissão de brotações e o desenvolvimento de raízes de gemas axilares da $c v$. Jewel de batata-doce (JARRET \& GAWEL, 1991).

Apesar de não terem sido detectadas diferenças significativas, em frascos vedados com papel alumínio, observaram-se menores valores numéricos de abscisão foliar na presença de ABA. Em frascos vedados com tampa plástica, na ausência de ABA, obteve-se menor abscisão foliar. A abscisão foliar variou de acordo com uma regressão quadrática, em função das concentrações de ABA com comportamento antagônico entre plantas mantidas em frascos vedados com tampa plástica e papel alumínio (Figura 1C).

O tipo de vedação de frasco interfere na aeração e na incidência de luminosidade para as culturas in vitro. Vedações que não são hermeticamente fechadas permitem maiores trocas gasosas entre o ar atmosférico e o ambiente do interior dos frascos, promovendo melhor transpiração das folhas e impedindo o acúmulo de etileno (FILHO et al., 2002).

Tanto para a vedação tipo tampa plástica quanto para o papel alumínio, a concentração de $0,5 \mathrm{mg}$ $\mathrm{L}^{-1}$ de ABA induziu menores valores numéricos para a abscisão (0,92 e 0,79, respectivamente). É possível que para a indução de um crescimento mínimo e manutenção de culturas viáveis sejam necessárias concentrações de ABA menores que $0,5 \mathrm{mg} \mathrm{L}^{-1}$.

Apesar das microestacas de mangabeira submetidas à ação do ABA terem sido avaliadas apenas por três meses, os resultados obtidos no presente trabalho indicam viabilidade para utilização do ABA em frascos com vedação de papel alumínio no processo de conservação in vitro de microestacas dessa espécie, sendo necessários estudos adicionais para testar o efeito desse regulador de crescimento por um maior período de tempo. 


\section{CONCLUSÃO}

O manitol nas concentrações de 10,15 e $20 \mathrm{~g}$ $\mathrm{L}^{-1}$ não é viável para a conservação in vitro de microestacas de mangabeira, uma vez que apresenta efeito tóxico sobre elas. O ácido abscísico na concentração de $0,5 \mathrm{mg} \mathrm{L}^{-1}$ apresenta viabilidade para a conservação in vitro de microestacas de mangabeira por um período de 90 dias, em frascos vedados com papel alumínio.

\section{AGRADECIMENTOS}

À Embrapa Tabuleiros Costeiros, à Fundação de Apoio à Pesquisa, à Inovação Tecnológica do Estado de SergipeFAPITEC/SE e ao Conselho Nacional de Desenvolvimento Científico e Tecnológico-CNPq (Processos n. 562728/2008-2, 474191/2007-9), pelo aporte de recursos financeiros e concessão de bolsa.

\section{REFERÊNCIAS}

CANTO, A.M.M.E. et al. Conservação in vitro de germoplasma de abacaxi tratado com paclobutrazol. Pesquisa Agropecuária Brasileira, Brasília, v.39, n.7, p.717-720, 2004. Disponível em: $<$ http://www.scielo.br/scielo.php?script=sci_arttext\&pid=S0100$204 X 2004000700014 \& \operatorname{lng}=\mathrm{en} \& \mathrm{nrm}=\mathrm{iso} \& \operatorname{lng}=\mathrm{pt}>$. Acesso em: 13 fev. 2010. doi: 10.1590/S0100-204X2004000700014.

FARIA, G.A. et al. Efeito da sacarose e do sorbitol na conservação in vitro de Plassiflora giberti N. E. Brown. Revista Brasileira de Fruticultura, v.28, n.2, p.267-270, 2006. Disponível em: $<$ http://www.scielo.br/scielo.php?script=sci_arttext\&pid=S0100$29452006000200025 \& \operatorname{lng}=\mathrm{en} \& \mathrm{nrm}=\mathrm{iso} \& \operatorname{lng} \mathrm{g}=\mathrm{pt}>$. Acesso em: 10 fev. 2010 . doi: 10.1590/S0100-29452006000200025.

FERREIRA, E.G. et al. Frutíferas. In: SAMPAIO, E.V.S.B. et al. (Org.). Espécies da flora nordestina de importância econômica potencial. Recife: Associação Plantas do Nordeste, 2005. p.49-100.

FILHO BUFFA, W. et al. Indução de metabólitos bioativos em culturas de células de Maytemus ticfolia. Eclética Química, São Paulo, v.27, n. especial, p.403-416, 2002. Disponível em: $<$ http://www.scielo.br/scielo.php? script=sci_arttext\&pid=S0100$46702002000200033 \& \operatorname{lng}=\mathrm{en} \& \mathrm{nrm}=\mathrm{iso} \& \mathrm{tlng}=\mathrm{pt}>$. Acesso em: 13 fev. 2010. doi: 10.1590/S0100-46702002000200033.

FORTES, G.R.L.; PEREIRA, J.E.S. Preservação in vitro de batata em ácido acetilsalicílico e duas fontes de carboidrato. Pesquisa Agropecuária Brasileira, Brasília, v.36, n.10, p.1261-1264, 2001. Disponível em: <http://www.scielo.br/ scielo.php? script=sci arttext\&pid=S 0100 204X2001001000007\&lng=en\&nrm=iso $>$. Acesso em: $10 \mathrm{fev}$. 2010. doi: $10.1590 / \mathrm{S} 0100204 \mathrm{X} 2001001000007$.

INIBAP. Global conservation strategy for Musa (banana and plantain). Montpellier: International Network for the Improvement of Banana and Plantain, 2006. 27p.

JARRET, R.L.; GAWEL, N. Abscisic acid-induced growth inhibition of sweet potato (Ipomoea batatas L.). Plant Cell, Tissue and Organ Culture, Netherlands, v.24, p.13-18, 1991.

LAMBARDI, M. et al. Medium- and long-term in vitro conservation of olive germplasm (Olea europaea L.). Acta Horticulturae, v.586, p.109-112, 2002. Disponível em: <http:/ /www.actahort.org/members/showpdf?booknrarnr=586_14>. Acesso em: 13 fev. 2010.

LEMOS, E.E.P de. et al. Conservação in vitro de germoplasma de cana-de-açúcar. Pesquisa Agropecuária Brasileira, Brasília, v.37, n.10, p.1359-1364, 2002. Disponível em: <http:/ $/$ www.scielo.br/scielo.php? script $=$ sci_arttext\&pid $=\mathrm{S} 0100$ $204 X 2002001000002 \& \operatorname{lng}=$ en\&nrm $=i s o>$. Acesso em: 15 fev. 2010. doi: $10.1590 / \mathrm{S} 0100-204 \mathrm{X} 2002001000002$.

LÉDO, A. da S. et al. Efeito da sacarose e do manitol na conservação in vitro por crescimento lento do coqueiro anão. Magistra, Cruz das Almas, v.19, p.346-351, 2007.

KERBAUY, G.B. Fisiologia vegetal. Rio de Janeiro: Guanabara Koogan, 2004. 452p.

NEPOMUCENO, C.F. et al. Controle da abscisão foliar e morfogênese in vitro em culturas de Anadenanthera colubrina (Vell.) Brenan var. cebil (Griseb) Altschul. Revista Árvore, Viçosa, v.31, n.5, p.967-975, 2007. Disponível em: <http:// www.scielo.br/scielo.php?script $=$ sci_arttext\&pid $=\mathrm{S} 0100$ $67622007000500021 \& \operatorname{lng}=$ en\&nrm $=i$ iso\&tlng $=p t>$. Acesso em: 13 fev. 2010. doi: 10.1590/S0100-67622007000500021.

OLIVEIRA, M. do S.P. et al. Viabilidade de pólen in vivo e in vitro em genótipos de açaizeiro. Acta Botânica Brasilica, São Paulo, v.15, n.1, p.27-33, 2001. Disponível em: <http:// www.scielo.br/scielo.php? script $=$ sci_arttext\&pid $=\mathrm{S} 0102$ $33062001000100004 \& \operatorname{lng}=\mathrm{en} \& \mathrm{nrm}=\mathrm{i}$ iso $\&$ tlng $=\mathrm{pt}>$. Acesso em: 13 fev. 2010. doi: 10.1590/S0102-33062001000100004.

RADEMACHER, W. Growth retardants: effects on gibberellin biosynthesis and other metabolic pathways. Annual Review of Plant Physiology and Plant Molecular Biology, Palo Alto, v.51, p.501-531, 2000. 